\title{
New Insights into the Management of Hypertension and Cardiovascular Risk with Angiotensin Receptor Blockers: Observational Studies Help Us?
}

\author{
Assen Goudev ${ }^{*}$
}

Department of Cardiology, Queen Giovanna University Hospital, 8 Bialo More St, Sofia 1527, Bulgaria

\begin{abstract}
Post-marketing observational studies are valuable for establishing the real-world effectiveness of treatment regimens in routine clinical practice as they typically monitor a diverse population of patients over many months. This article reviews recent observational studies of angiotensin receptor blockers (ARBs) for the management of hypertension: the 6-month eprosartan POWER study $(\mathrm{n} \sim 29,400)$, the 3-month valsartan translational research programme $(\mathrm{n} \sim 19,500)$, the 9-month irbesartan Treat to Target study $(\mathrm{n}=14,200)$, the 6-month irbesartan DO-IT survey ( $\mathrm{n} \sim 3300)$ and the 12-week candesartan CHILI survey programme $(n=4600)$. Reduction in blood pressure with ARBs reported across these studies appears to be comparable for the different agents, although direct comparisons between studies cannot be made owing to different treatment durations and baseline patient demographics. Of these studies, the eprosartan POWER study, 2 of the 7 studies in the valsartan translational research programme, and the candesartan CHILI Triple T study measured total cardiovascular risk, as recommended in the 2013 European Society of Cardiology-European Society of Hypertension guidelines. The POWER study confirmed the value of the Systemic Coronary Risk Evaluation (SCORE) to accurately assess total cardiovascular risk.

With the advent of new healthcare practices, such as the use of electronic health records (EHRs), observational studies in larger patient populations will become possible. In the future, algorithms embedded in EHR systems could evolve as decision support tools to inform on patient care.
\end{abstract}

Keywords: Angiotensin receptor blockers, blood pressure, candesartan, eprosartan, irbesartan, observational studies, Systemic Coronary Risk Evaluation, valsartan.

\section{INTRODUCTION}

There is a common perception within the scientific community that observational studies overestimate treatment effects and as such, the validity of studies is often widely disputed $[1,2]$. However, with the advent of new healthcare practices, such as the use of electronic health records (EHRs), observational studies with novel statistics conducted in much larger study populations will be possible and will allow conclusions to be drawn from observed trends [3]. In this article, the role of observational studies in cardiovascular (CV) research will be discussed and a critical review of recent observational studies with angiotensin receptor blockers (ARBs) will be presented. The main focus of the search strategy was to select a range of different ARBs to be compared: MEDLINE was searched for recent observational studies of ARBs involving large patient populations using the search terms 'angiotensin receptor blocker', 'observational study' and 'clinical practice'.

\section{ROLE OF OBSERVATIONAL STUDIES IN CARDIO- VASCULAR RESEARCH}

Controlled clinical trials are often considered as the gold standard to evaluate the safety and efficacy of new treatments. However, there are limitations to their use. For

\footnotetext{
*Address correspondence to this author at the Department of Cardiology, Queen Giovanna University Hospital, 8 Bialo More St, Sofia 1527, Bulgaria; Tel: +35929432584; Fax: +35929432126; E-mail: goudev@abv.bg
}

example, while the strict eligibility criteria for clinical trials reduce the influence of patient variability on outcome measures, these patient populations do not reflect the general population and/or those who may be prescribed the treatment in clinical practice. Therefore, it is possible that some treatment effects may not be detected during a clinical trial setting. In $\mathrm{CV}$ research, clinical trials for antihypertensive therapies do not always report total CV risk. The importance of total CV risk has been reaffirmed in the new guidelines for the management of hypertension issued jointly by the European Society of Cardiology and the European Society of Hypertension (ESC/ESH) [4]. Guidelines should be used to advise the selection of patients requiring treatment and to select the intensity of antihypertensive treatment regimens [4]. Observational studies offer some advantages over clinical trials [5]. Specifically, the follow-up period is often much longer than that of a clinical trial, therefore observational studies are more likely to detect rare adverse events or those caused by long-term treatment. In addition, observational studies are often conducted in routine clinical practice where the diversity of patients is much wider than in a clinical trial. Treatment effects, for example those associated with comorbidities or concomitant medications not permitted in a clinical trial, may be identified during an observational study thereby providing invaluable information.

Approximately $90 \%$ of research papers published in clinical speciality journals describe results from observational studies [5]. Evaluation of 99 reports, across 5 different 
clinical areas, by Concato and colleagues demonstrated that well-designed observational studies do not overestimate the magnitude of treatment effects compared with randomised controlled trials in the same clinical field [2]. In addition, Golder and colleagues reported that observational studies and randomised controlled trials appear to result in similar risk estimates for adverse events, which suggests that systematic reviews of adverse events should not be limited to clinical trials alone [1].

Clinical trials and observational studies therefore play valuable but distinct roles in providing evidence on treatment effects and neither should be considered in isolation when evaluating the overall efficacy and safety of treatments. With the recent publication of guidelines for performing observational studies [6] and the Strengthening the Reporting of Observational Studies in Epidemiology (STROBE) statement [5], physicians are better supported to assess the value of observational research and to have confidence in their results.

\section{REVIEW OF RECENT OBSERVATIONAL STUDIES OF ARBs}

The study designs and objectives of selected recent observational studies evaluating ARBs are provided in (Table 1). The following section will summarise the study objectives, design and results for each study:

\section{Eprosartan POWER Study}

\section{Objectives}

The primary objective of the Physicians' Observational Work on Patient Education According to their Vascular Risk (POWER) study was to evaluate the change in systolic blood pressure (SBP) following treatment with eprosartan-based antihypertensive therapy for 6 months in a large population from countries with differing levels of total CV risk. The secondary objective of the study was to assess the total CV risk.

\section{Study Design}

The POWER study was a 6-month open-label, postmarketing surveillance study. Details of the study design and methodology are described elsewhere [7]. In brief, patients with mild-to-moderate hypertension (mean sitting SBP $>140$ $\mathrm{mmHg}$ ) treated with eprosartan were recruited by general physicians (GPs) or cardiologists from 16 countries within Europe, the Middle East, Asia, Africa and North America. Patients were either newly diagnosed with hypertension or were unresponsive to or intolerant of their current antihypertensive treatment. Initial treatment was with eprosartan monotherapy (600 mg/day). If patients had inadequate blood pressure (BP) control after 1 month of treatment with eprosartan monotherapy, other antihypertensive agents (preferably hydrochlorothiazide [HCTZ] $12.5 \mathrm{mg}$ /day) could be prescribed. Physicians retained the discretion to use other interventions such as lipid-modifying agents and smoking cessation initiatives.

Response to eprosartan-based therapy was defined as achievement of SBP $<140 \mathrm{mmHg}$ and/or a reduction in SBP $\geq 15 \mathrm{mmHg}$ or diastolic blood pressure (DBP) $<90 \mathrm{mmHg}$ and/or reduction in $\mathrm{DBP} \geq 10 \mathrm{mmHg}$. The change in $\mathrm{CV}$ risk after 6 months of treatment was calculated using either the Systemic Coronary Risk Evaluation (SCORE) [8] method or the Framingham score [9] (Canadian cohort only).

\section{Results}

Of the 29,370 patients included in the safety population, 26,192 patients were eligible for the intention-to-treat (ITT) cohort [10]. The mean age of the ITT population was 61.3 years and $52 \%$ of patients were male. Men had a significantly lower mean age compared with women (59.5 vs 63.3 years; $\mathrm{p}<0.01)$. There was also a difference in age distribution between the sexes, with women representing proportionally more $(59 \%)$ of the older ( $>70$ years) age group and men representing proportionally more $(63 \%)$ of the 50-59 years age group.

Mean baseline arterial BP was $160.4 \pm 14.3 / 93.6 \pm 9.7$ $\mathrm{mmHg}$ and mean pulse pressure was $66.9 \pm 14.3 \mathrm{mmHg}$. SBP increased with age whereas DBP decreased with age, hence pulse pressure increased with age. Systo-diastolic hypertension and isolated systolic hypertension were recorded in $73 \%$ and $25 \%$ of patients, respectively. CV-relevant pathologies included diabetes (23\%), left ventricular hypertrophy $(19 \%)$ and arteriosclerosis (19\%). There was a family history of $\mathrm{CV}$ disease in $40 \%$ of patients and $25 \%$ of all patients were smokers [10].

\section{Treatments Prescribed}

Approximately one-third of patients were assigned each to eprosartan monotherapy, dual therapy or multiple therapies. The most commonly prescribed supplementary drugs were beta-blockers, calcium antagonists, HCTZ or other diuretics, and angiotensin-converting enzyme inhibitors. The use of combination therapy was more common in men, in older or diabetic patients, and in those with a significant history of CV disease.

\section{Key Efficacy Results}

Mean SBP in the ITT population decreased by $25.8 \pm 14.4 \mathrm{mmHg}$ after 6 months' treatment $(\mathrm{p}<0.001$ vs baseline) (Fig. 1A). Significant reductions in the mean DBP $(12.6 \pm 9.5 \mathrm{mmHg})$ and pulse pressure $(13.2 \pm 13.5 \mathrm{mmHg})$ were also observed at 6 months (both $p<0.01$ vs baseline) (Fig. 1A). Antihypertensive treatment efficacy was demonstrated in all patient subsets, including those with diabetes or other forms of high baseline CV risk [10].

At the end of the observation period, approximately $62 \%$ of patients achieved the predefined target of SBP $<140$ $\mathrm{mmHg}$ and DBP $<90 \mathrm{mmHg}$, and over $90 \%$ of patients were classified as 'responders' to eprosartan-based therapy.

The calculated total CV risk (SCORE or Framingham) reduced in parallel with the eprosartan-related reduction in SBP. In those patients for whom the SCORE risk estimation was applicable $(n=12,718)$, the mean chart-based SCORE value was $6.0 \% \pm 5.8 \%$ at baseline compared with $3.5 \% \pm 3.5 \%$ after 6 months of treatment, corresponding to an absolute reduction of $2.4 \% \pm 3.1 \%$ and a relative reduction in $\mathrm{CV}$ risk of $38.4 \%$ [11].

SCORE risk was stratified into 4 categories: low risk $(<1 \%)$, moderate risk $(1-4 \%)$, high risk $(5-9 \%)$ and very high 
Table 1. Comparison of recent observational studies of angiotensin receptor blockers.

\begin{tabular}{|c|c|c|c|c|}
\hline Name (references) & Agent & Study design & $\begin{array}{c}\text { Objective/ } \\
\text { Primary endpoint }\end{array}$ & Key points \\
\hline POWER $[10,11]$ & $\begin{array}{l}\text { Eprosartan (eprosartan } \\
600 \mathrm{mg} / \text { day monotherapy or } \\
\text { in combination with HCTZ } \\
12.5 \mathrm{mg} / \text { day) }\end{array}$ & $\begin{array}{l}\text { 6-month open-label observa- } \\
\text { tional study in } 16 \text { countries } \\
\text { worldwide } \\
(n>29,000)\end{array}$ & $\begin{array}{l}\text { Absolute change in SBP over } \\
6 \text { months of treatment and its } \\
\text { impact on total cardiovascular } \\
\text { risk }\end{array}$ & $\begin{array}{l}\text { Significant reduction in SBP } \\
\text { was irrespective of patient } \\
\text { sex, age, diabetic status or } \\
\text { cardiovascular history }\end{array}$ \\
\hline $\begin{array}{l}\text { Treat to Target } \\
\text { study [15] }\end{array}$ & $\begin{array}{l}\text { Irbesartan (irbesartan } 75 \text {, } \\
150 \text { or } 300 \text { mg as monother- } \\
\text { apy or in combination with } \\
\text { HCTZ } 12.5 \mathrm{mg} \text { ) }\end{array}$ & $\begin{array}{l}\text { Prospective, two-armed, post- } \\
\text { authorisation 9-month observa- } \\
\text { tional study conducted in Ger- } \\
\text { many }(n=14,200)\end{array}$ & $\begin{array}{l}\text { Change in SBP and DBP after } \\
9 \text { months of treatment and its } \\
\text { impact on criteria for the meta- } \\
\text { bolic syndrome }\end{array}$ & $\begin{array}{l}\text { Irbesartan monotherapy and } \\
\text { in combination with HCTZ } \\
\text { significantly reduced both } \\
\text { SBP and DBP. The number of } \\
\text { patients with the metabolic } \\
\text { syndrome was reduced at the } \\
\text { end of the observation period }\end{array}$ \\
\hline DO-IT survey [16] & $\begin{array}{l}\text { Irbesartan (irbesartan } \\
150 \mathrm{mg} \text { or } 300 \mathrm{mg} \text { daily } \\
\text { with or without HCTZ } \\
12.5 \mathrm{mg} \text { daily) }\end{array}$ & $\begin{array}{l}\text { Prospective, observational, } \\
6 \text {-month study in Germany } \\
(\mathrm{n}=3259)\end{array}$ & $\begin{array}{l}\text { Change in blood pressure and } \\
\text { metabolic parameters after } \\
6 \text { months of treatment in pa- } \\
\text { tients with the metabolic syn- } \\
\text { drome }\end{array}$ & $\begin{array}{l}\text { Treatment resulted in signifi- } \\
\text { cant reductions in SBP and } \\
\text { DBP and improved metabolic } \\
\text { measures }\end{array}$ \\
\hline $\begin{array}{l}\text { CHILI Triple } T \\
\text { survey programme } \\
{[18]}\end{array}$ & $\begin{array}{l}\text { Candesartan cilexetil (can- } \\
\text { desartan cilexetil } 16 \mathrm{mg}+ \\
\text { HCTZ } 12.5 \mathrm{mg} \text { [fixed-dose } \\
\text { combination] or candesartan } \\
\text { cilexetil } 32 \mathrm{mg} \text { [high-dose } \\
\text { monotherapy]) }\end{array}$ & $\begin{array}{l}\text { Prospective, non- } \\
\text { interventional, uncontrolled, } \\
\text { open-label, } 12 \text {-week observa- } \\
\text { tional study in Germany (fixed- } \\
\text { dose combination, } n=3337 \text {; } \\
\text { high-dose monotherapy, } \\
\mathrm{n}=1263 \text { ) }\end{array}$ & $\begin{array}{l}\text { Change from baseline in blood } \\
\text { pressure (SBP and DBP) and } \\
\text { cardiovascular risk }\end{array}$ & $\begin{array}{l}\text { Both fixed-dose combination } \\
\text { therapy and high-dose mono- } \\
\text { therapy effectively reduced } \\
\text { blood pressure in patients at } \\
\text { increased risk of cardiovascu- } \\
\text { lar events }\end{array}$ \\
\hline
\end{tabular}

DBP, diastolic blood pressure; HCTZ, hydrochlorothiazide; SBP, systolic blood pressure.

risk $(\geq 10 \%)$. Analysis of the SCORE risk distribution at baseline and 6 months (Fig. 2) shows the change in distribution of $\mathrm{CV}$ risk distribution after 6 months of treatment. Three-quarters of patients initially classified as being at very high risk were reclassified to lower risk groups, of whom $11 \%$ were reclassified 2 categories below very high risk [11].

\section{Safety}

Eprosartan therapy, either alone or in combination with other antihypertensive treatments, was well tolerated. Adverse events were recorded in less than $2 \%$ of patients, twothirds of which were recorded as suspected adverse drug reactions. Importantly, no new adverse drug reactions were identified in the safety population [10].

\section{Valsartan Translational Research Programme}

A translational research programme, comprising 7 observational studies on various valsartan regimens (monotherapy as well as single and separate pill combinations) was reviewed by Abraham and colleagues [12].

\section{Objectives}

The core objectives across the 7 studies were to assess SBP and DBP control at 90 days in patients receiving valsar- tan after failure of or intolerance to previous hypertensive treatment; to determine the percentage of variance in BP at 90 days attributable to a physician class effect; to examine the hierarchical determinants of BP at 90 days; and to identify independent predictors of non-response to valsartanbased treatment. In 2 of the studies (BSCORE and EXCELLENT) physician-reported total $\mathrm{CV}$ risk was assessed $[13,14]$.

\section{Designs}

All 7 studies were conducted in Belgium using the same methodological and statistical methods. The studies included a baseline assessment at initiation of valsartan treatment, and a follow-up assessment after approximately 90 days. The studies included only patient data collected as part of routine clinical practice.

Each study examined the impact of valsartan-based treatment regimens on SBP and DBP values and BP control, as defined by the 2007 ESC guidelines at the time the studies were conducted (SBP $<140 \mathrm{mmHg}$ and/or DBP $<90 \mathrm{mmHg}$, except for patients with diabetes mellitus and/or a high or very high $\mathrm{CV}$ risk, in which case targets were $130 / 80 \mathrm{mmHg}$ ). 
A Eprosartan-based therapy in the POWER study

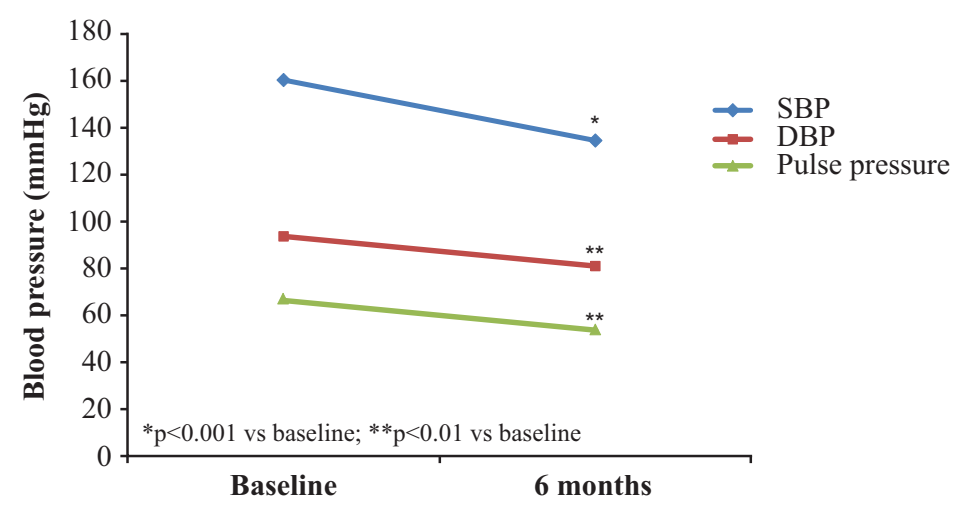

B Valsartan-based therapy in the translational research programme

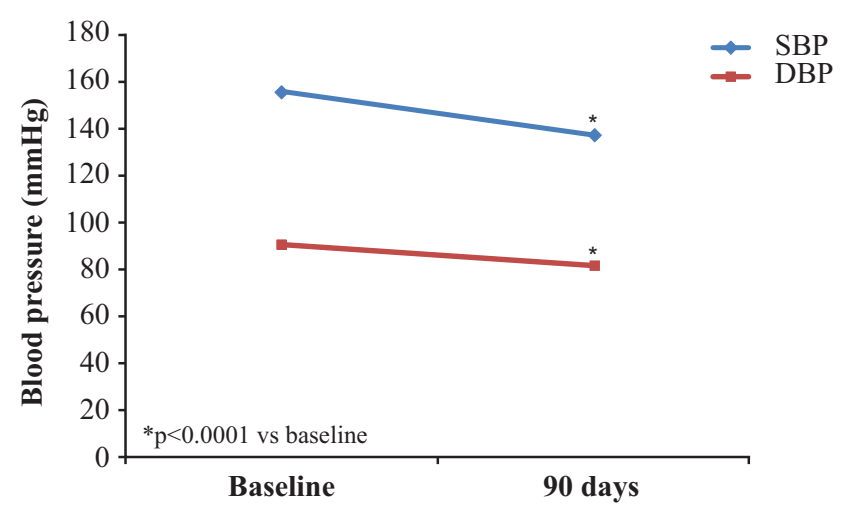

$\mathrm{C}$

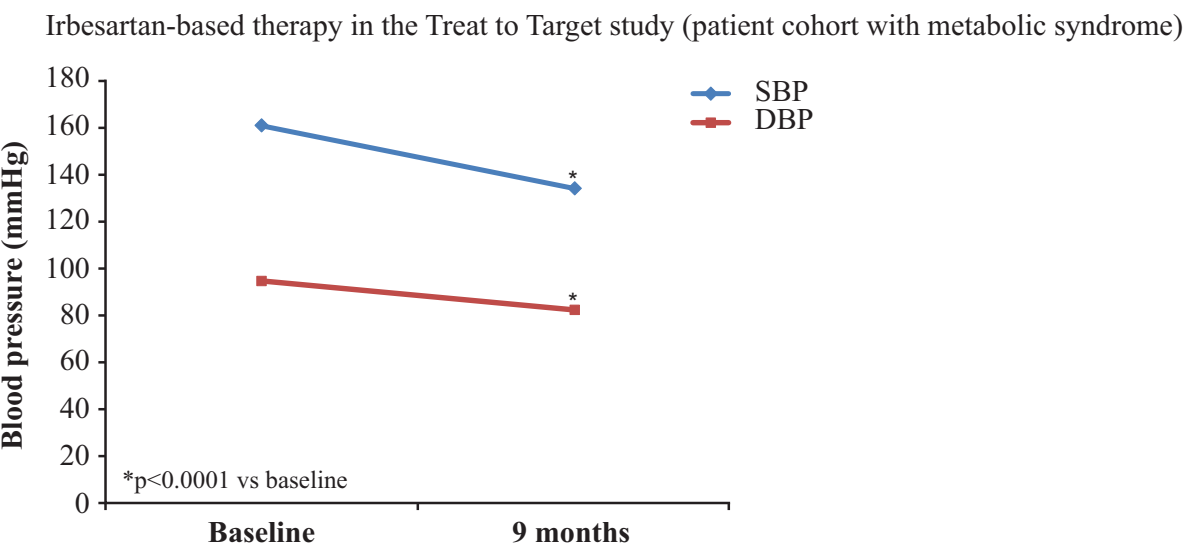

Fig. (1). Reduction in blood pressure with angiotensin receptor blockers in observational studies [10, 12, 15]. DBP, diastolic blood pressure; SBP, systolic blood pressure.

The 7 studies all included advanced modelling techniques to identify determinants of BP outcomes and CV risk, where relevant. Using a statistical hierarchical approach, in which patients were grouped under their treating physicians, the investigators examined both physician- and patientrelated determinants of uncontrolled BP at 90 days and independent predictors of improved $\mathrm{CV}$ risk (BSCORE and EXCELLENT studies only).

\section{Results}

A total of 19,533 evaluable patients were contributed by 3434 physicians across the seven studies; the weighted average for age was $63.6( \pm 12)$ years, $50.3 \%$ of patients were male and $23.7 \%$ were diabetic.

SBP and DBP values at baseline and after 90 days of valsartan-based treatment were similar across the seven studies. 
Using weighted averages, SBP decreased from a mean $( \pm$ SD) of $155.9 \pm 15.4 \mathrm{mmHg}$ to $137.5 \pm 11.8 \mathrm{mmHg}$, while DBP decreased from $91.5 \pm 9.6 \mathrm{mmHg}$ to $82.0 \pm 7.5 \mathrm{mmHg}$ (Fig. 1B). Valsartan regimens were associated with absolute reductions in mean SBP of $-18.4 \mathrm{mmHg}(\mathrm{p}<0.0001)$ and mean DBP of $-9.5 \mathrm{mmHg}(\mathrm{p}<0.0001)$ compared with baseline values. At 90 days, $38.2 \%$ of patients had controlled SBP, $58.2 \%$ of patients had controlled DBP and $32.0 \%$ of patients had both controlled SBP and DBP.

Combined data from the BSCORE and EXCELLENT studies showed that the total CV risk classification decreased by $0.74 \pm 0.95$ of a category after 90 days of antihypertensive treatment. Over this period, the total CV risk was reduced by at least one category from baseline in $59.5 \%$ of patients. Improvements in total CV risk from baseline were statistically significant for both studies $(p<0.0001)$.

The evidence from the translational programme was robust, with the findings being persistent across time, different formulations, patients and clinicians.

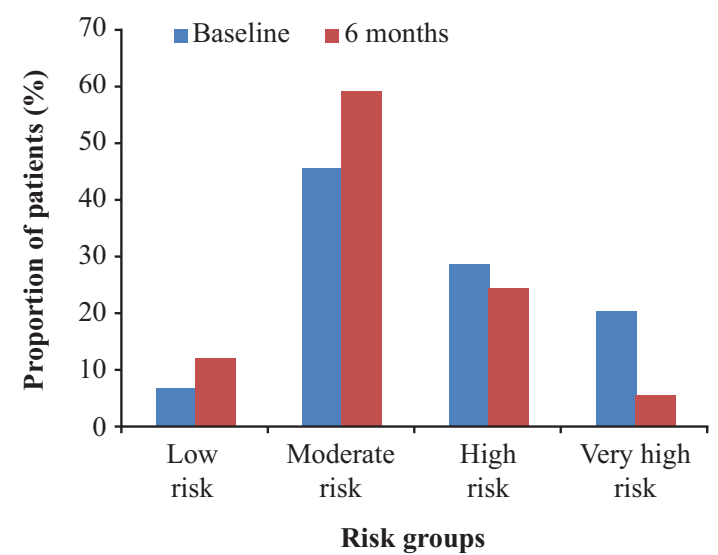

Fig. (2). Chart-based estimates of SCORE risk distributions in the POWER survey at baseline and after 6 months of treatment with eprosartan-based therapy. Estimates are based on $n=12,718$ at baseline and $\mathrm{n}=9577$ at 6 months. Low risk, $<1 \%$; moderate risk, $1-4 \%$; high risk, 5-9\%; very high risk, $\geq 10 \%$ [11].

\section{Irbesartan Treat to Target Study Objectives}

The main objectives of this study were to investigate the effect of irbesartan, either as a monotherapy or in combination with HCTZ on: BP response, metabolic parameters and resultant changes in CV risk factors [15].

\section{Design}

The study was a prospective, two-armed, postauthorisation 9-month study in patients with uncontrolled hypertension with the metabolic syndrome. Patients with uncontrolled hypertension but without the metabolic syndrome served as controls. It was conducted as an observational study in primary care by 3609 GPs in Germany. Patients were treated with once-daily irbesartan 75,150 or $300 \mathrm{mg}$ as monotherapy or in combination with HCTZ $12.5 \mathrm{mg}$, and additional antihypertensive medication was permitted. There were no specifications regarding BP targets, although many of the physicians followed the national guidelines.
SBP and DBP were measured at baseline and after 3 and 9 months of treatment. The following CV risk factors that make up the criteria for the metabolic syndrome were measured: changes in fasting glucose, waist circumference (a measure of abdominal obesity), serum triglycerides and high-density lipoprotein cholesterol (HDL-C). The proportion of patients fulfilling the criteria for the metabolic syndrome was also assessed.

\section{Results}

During the observation period (January 2005-July 2006), a total of 14,200 patients were documented, of whom 9281 had the metabolic syndrome and 4919 served as controls. The proportion of men and women and the mean age between the 2 groups were well balanced. Mean body mass index and waist circumference were higher in patients with the metabolic syndrome compared with the control group.

Overall, approximately $80 \%$ of all patients in the study received treatment with the highest dose of irbesartan $(300 \mathrm{mg})$, either alone or in combination with HCTZ.

In patients with the metabolic syndrome, treatment with either irbesartan monotherapy or irbesartan in combination with HCTZ for 9 months resulted in significant reductions in BP. Irbesartan monotherapy reduced SBP and DBP by 26.3 $\pm 10.1 \mathrm{mmHg}$ and $13.0 \pm 6.6 \mathrm{mmHg}$, respectively (both $\mathrm{p}<0.0001$ ) (Fig. 1C). Irbesartan in combination with $12.5 \mathrm{mg}$ HCTZ reduced SBP and DBP by $27.5 \pm 10.1 \mathrm{mmHg}$ and $14.1 \pm 6.6 \mathrm{mmHg}$, respectively (both $\mathrm{p}<0.0001$ ).

Improvements in CV risk factors were observed with irbesartan monotherapy and were more pronounced in those patients with the metabolic syndrome. The addition of HCTZ to irbesartan in this cohort resulted in similar improvements in these parameters. Consequentially, there was a marked reduction in the number of patients fulfilling the criteria for the metabolic syndrome at the end of the observation period.

The overall tolerability throughout the study was very good with only $0.6 \%$ and $0.24 \%$ of patients reporting adverse events or serious adverse events, respectively.

These data are consistent with those reported for the DO-IT prospective, observational study, also conducted in Germany. In this study, the effect of 6 months of irbesartan treatment (150 or $300 \mathrm{mg}$ daily) with or without HCTZ (12.5 mg daily) on BP and metabolic parameters was evaluated in patients with the metabolic syndrome $(n=3259)[16]$. Within the observation period, SBP decreased from $157.4 \pm$ $14.7 \mathrm{mmHg}$ to $135.0 \pm 10.9 \mathrm{mmHg}(-22.4 \mathrm{mmHg})$ and DBP decreased from $92.9 \pm 9.2 \mathrm{mmHg}$ to $80.8 \pm 6.8 \mathrm{mmHg}$ $(-12.1 \mathrm{mmHg})$. The proportion of patients with SBP $<130$ $\mathrm{mmHg}$ increased from $1.6 \%$ at baseline to $20.4 \%$ after treatment, while the proportion of patients with SBP $>180$ $\mathrm{mmHg}$ decreased from $9.4 \%$ to $0.4 \%$. Similarly, DBP was $<85 \mathrm{mmHg}$ in $15.7 \%$ of patients at baseline compared with $67 \%$ of patients at 6 months. The proportion of patients who had BP readings of $<140 / 90 \mathrm{mmHg}$ increased from $4.9 \%$ at baseline to $59.2 \%$ after 6 months of treatment. Improvements in metabolic parameters were also reported and were more pronounced in those patients who received the higher dose of irbesartan. An earlier observational study of 3 months' irbe- 
sartan treatment in patients with hypertension and type 2 diabetes $(n=16,600)$ reported a reduction in SBP/DBP together with a reduction in total $\mathrm{CV}$ risk, assessed using SCORE [17].

\section{Candesartan CHILI Triple T Study}

\section{Objectives}

The main objective of the CHILI (Candesartan in patients with Higher cardiovascular risk)Triple T study was to evaluate the efficacy and safety of candesartan cilexetil in a combination treatment regimen or as a high-dose monotherapy. The 2 treatment strategies were compared for achievement of BP targets in all patients, and for attaining BP targets in patient subgroups with different CV risks at baseline [18].

\section{Design}

The study was a prospective, non-interventional, uncontrolled, open-label, observational study conducted by GPs, internists or diabetologists in Germany. Patients with uncontrolled hypertension and added CV risk received a fixed-dose combination of candesartan cilexetil $16 \mathrm{mg}$ and HCTZ $12.5 \mathrm{mg}$ (combination therapy group) or candesartan cilexetil $32 \mathrm{mg}$ (high-dose monotherapy group).

\section{Results}

A total of 4600 patients (3337 in the combination therapy group; 1263 in the high-dose monotherapy group) were included in the study (safety population) of which 4527 were eligible for efficacy analyses. Mean age was $63.1 \pm 11.0$ years and $55.3 \%$ of patients were male. Patients in the 2 treatment groups were comparable with respect to age and gender, but patients receiving high-dose monotherapy had a slightly higher mean SBP, more prior revascularisations, renal insufficiency, diabetic nephropathy, peripheral artery disease and a lower ankle brachial index.

Treatment with the combination therapy regimen reduced SBP by $28.5 \pm 13.8 \mathrm{mmHg}$ and DBP by $14.2 \pm 9.4 \mathrm{mmHg}$ $(\mathrm{p}<0.001$ vs baseline values of SBP $160.2 \pm 13.3$ and DBP $94.5 \pm 8.2 \mathrm{mmHg}$ ). High-dose monotherapy was also effective in reducing BP with reductions in SBP and DBP of $29.73 \pm 15.3$ and $14.1 \pm 9.6 \mathrm{mmHg}$, respectively $(\mathrm{p}<0.001 \mathrm{vs}$ baseline values of SBP $162.4 \pm 14.7$ and DBP $94.7 \pm 8.7$ $\mathrm{mmHg}$ ).

Both the combination therapy and high-dose monotherapy groups had mostly high or very high added CV risk at baseline (see Fig. 3), as defined by BP readings and the presence of comorbid risk factors and disease according to the ESC/ESH 2007 guidelines [19]. CV risk was substantially reduced at the 12 -week follow-up $(\mathrm{p}<0.001$ vs baseline in both groups) with substantially fewer patients having high or very high added risk, and more patients having low or moderate added risk.

Overall tolerability throughout the study was very good with only $0.8 \%$ of patients in the combination therapy group and $1.2 \%$ in the high-dose monotherapy group experiencing an adverse event.

\section{COMPARISON OF OBSERVATIONAL STUDIES}

Post-marketing observational studies are valuable for establishing the real-world effectiveness of treatment regimens as they typically monitor a diverse population of patients over many months or even years. ARBs are routinely prescribed by both cardiologists and GPs, and regular monitoring occurs in routine clinical practice.

A Patients receiving candesartan/hydrochlorothiazide

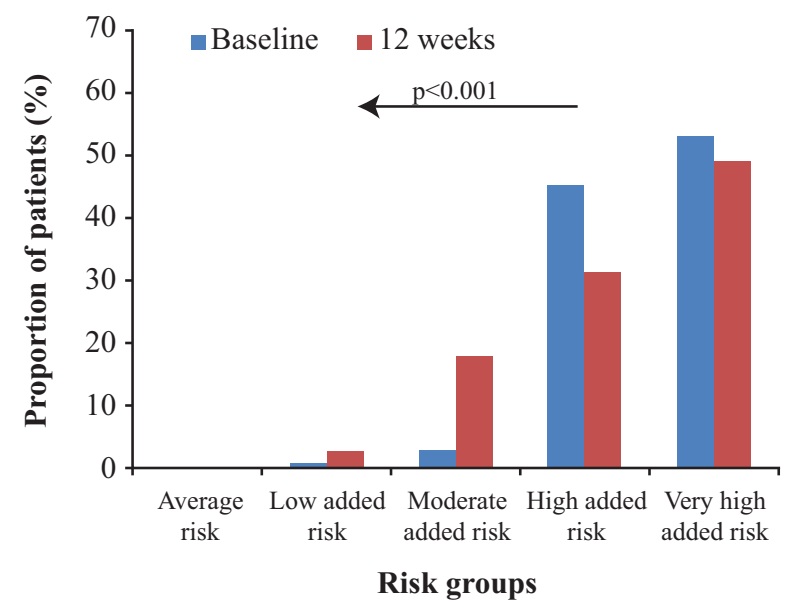

B Patients receiving candesartan $32 \mathrm{mg}$

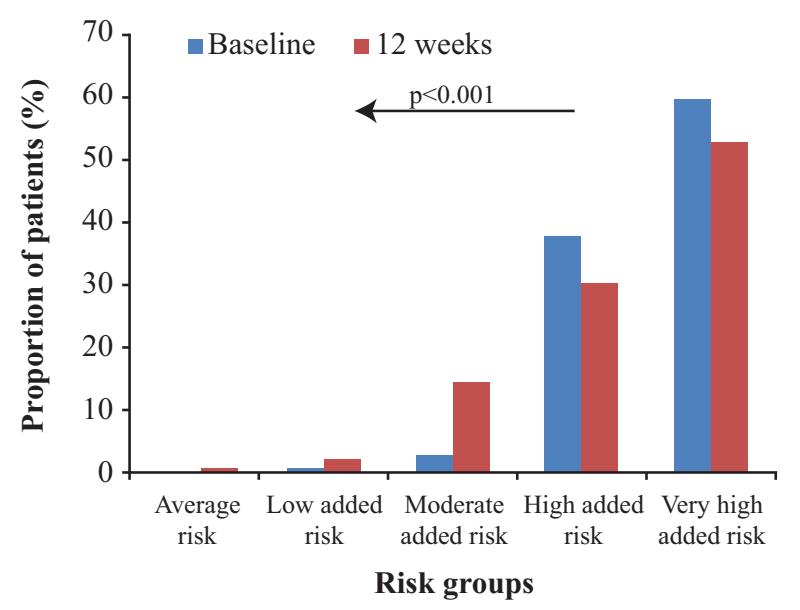

Fig. (3). Cardiovascular risk (\%) at baseline and after follow-up in the CHILI Triple T study [18] according to the European Society of Hypertension/European Society of Cardiology 2007 guidelines [19]. (A) Patients receiving candesartan/hydrochlorothiazide; (B) patients receiving candesartan $32 \mathrm{mg}$. Stratification of cardiovascular risk in four categories. Low, moderate, high and very high added risk refers to 10 -year risk of a cardiovascular fatal or non-fatal event.

The 2013 guidelines from the ESC/ESH recommend that total CV risk is assessed systematically in all patients with arterial hypertension, for example by using the SCORE model. In addition, they recommend that the intensity of antihypertensive management is graded as a function of this risk [4]. Some, but not all, of the recent observational studies of ARBs presented in this review have reported measures of total CV risk (see Table 2). The relevance of those studies without total CV risk analyses, in terms of providing realworld insight, could be questioned since this measure is 
Table 2. Key observational studies of angiotensin receptor blockers: measures of cardiovascular risk.

\begin{tabular}{|c|c|}
\hline Studies that reported changes in total cardiovascular risk: & Studies that reported changes in cardiovascular risk parameters: \\
\hline 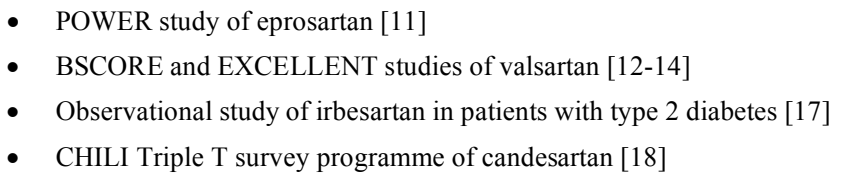 & $\begin{array}{l}\text { - Valsartan Translational Research Programme (excluding BSCORE and } \\
\text { EXCELLENT studies) [12] } \\
\text { - Treat to Target post-authorisation survey of irbesartan [15] } \\
\text { - } \quad \text { DO-IT survey of irbesartan [16] }\end{array}$ \\
\hline
\end{tabular}

pivotal to inform treatment decisions for hypertensive patients in daily practice.

The reduction in BP with ARB treatment reported across the different observational studies in this review appears to be comparable for the different agents. However, direct comparisons cannot be made owing to different durations of treatment (from 3 to 9 months) and differences in patient groups at baseline, for example different $\mathrm{CV}$ risk parameters and $\mathrm{CV}$ disorders. Of the observational studies on ARBs reviewed in this article, the POWER study with over 29,000 patients was the largest.

\section{Selection of Cardiovascular Risk Assessments Advantages of SCORE}

There are many advantages of using SCORE to calculate $\mathrm{CV}$ risk in patients. SCORE provides clinicians with a practical approach to identify those patients at high risk of a fatal cardiovascular event; the colour-coded SCORE risk charts are in a simple format that makes it easy for clinicians to estimate CV risk using routine clinical measurements [8]. Furthermore, SCORE is available as an electronic version that can be used online or downloaded from the website (www.heartscore.org).

SCORE was derived from 12 European cohort studies with a total of 205178 patients representing 2.7 million person years of follow-up [8]. It uses SBP to estimate total CV risk and there is evidence to suggest that SBP rather than DBP is a better predictor of CV events [20]. Since its derivation, SCORE has been validated in numerous external studies in different countries and has shown good discrimination between people at high and low risk of a cardiovascular event [21]. SCORE can also be adapted for country-specific use; SCORE risk charts are available for high-risk and lowrisk European countries [8] and this tool has also been successfully calibrated for use in individual countries [22,23].

\section{Limitations of SCORE}

A limitation of SCORE is that it only takes into consideration principal risk factors; other risk factors, such as a strong family history of early-onset CV disease, milder degrees of impaired glucose regulation, triglyceride levels and fibronectin, should also be considered [8]. Another limitation of SCORE, also noted for other risk scores, is that the effect of other medication (on CV risk) is not fully assessed and adjusted for. Ideally, medication used prior to the study and medication started during the study follow-up should be factored into the SCORE risk charts [24].

Some studies have demonstrated that SCORE may underestimate CV risk in specific patient groups. Szyndler and colleagues demonstrated that, when compared with the ESC/ESH hypertension guidelines, SCORE underestimated the burden of $\mathrm{CV}$ risk among hypertensive patients, particularly women [25]. Furthermore, a comparison of SCORE with the Framingham-D'Agostino CV scale revealed that SCORE may underestimate CV risk in men who have an unfavourable blood lipid profile [26].

\section{Role of Framingham Risk Assessment}

The Framingham risk algorithm was originally derived from participants of the Framingham Heart Study in the USA (1971-1974) which included 2489 men and 2856 women [9]. It has been assessed and validated in numerous external studies and has shown good discrimination between high- and low-risk patients [21]. The Framingham risk score may be more suitable for use in a North American population, including in Canada. Indeed, Grover and colleagues have demonstrated that the Framingham risk score was able to show good discrimination in a Canadian cohort [27].

\section{CLINICAL INSIGHTS FROM OBSERVATIONAL STUDIES OF ARBs}

The observational studies reviewed here confirm that ARB-based therapy reduces SBP and DBP in large, unselected primary care populations. Reduction of SBP has been previously correlated with regression of left ventricular hypertrophy and improvement of CV outcomes [28-32]. A proportion of these observational studies also reported a benefit of ARBs on total CV risk [10-14, 17, 18], a measure recommended by the ESC/ESH guidelines published in 2013 [4]. In particular, the POWER study confirmed that physicians can use SCORE accurately to assess total CV risk, as shown by the comparisons of recorded and calculated SCORE risk [11]. Results from the POWER study, the BSCORE and EXCELLENT studies in the valsartan translational research programme, and the candesartan CHILI Triple T study demonstrate the importance and value of measuring total CV risk before and after treatment, suggesting that these assessments should be performed in future $\mathrm{CV}$ studies.

New healthcare practices, such as the use of EHRs, will facilitate observational studies in much larger patient populations. Algorithms embedded in EHR systems will serve to inform patient care and will continuously evolve in agreement with clinical observations and new research. These algorithms will be derived entirely from large pools of data, making it possible to draw conclusions from observed trends. In the future, it is anticipated that these algorithms will evolve as decision support tools to enable large observational studies to be conducted with less direct involvement of physicians and less inconvenience for the patient.

\section{CONFLICT OF INTEREST}

The author confirms that this article content has no conflicts of interest. 


\section{ACKNOWLEDGEMENTS}

The author acknowledges editorial support provided by Adelphi Communications Ltd, UK, supported by Abbott Products Operations AG, Allschwil, Switzerland.

The development of this article was supported by an unrestricted educational grant from Abbott Products Operations AG, Allschwil, Switzerland. Abbott had no control over the content of this review and Professor Goudev received no payment for any part of his work on this article.

\section{PATIENT'S CONSENT}

Declared none.

\section{REFERENCES}

[1] Golder S, Loke YK, Bland M. Meta-analyses of adverse effects data derived from randomised controlled trials as compared to observational studies: methodological overview. PLoS Med 2011; 8(5): e1001026.

[2] Concato J, Shah N, Horwitz RI. Randomized, controlled trials, observational studies, and the hierarchy of research designs. N Engl J Med 2000; 342(25): 1887-92.

[3] Kohane IS, Drazen JM, Campion EW. A glimpse of the next 100 years in medicine. N Engl J Med 2012; 367(26): 2538-9.

[4] Mancia G, Fagard R, Narkiewicz K, et al. 2013 ESH/ESC Guidelines for the Management of Arterial Hypertension: the task force for the management of arterial hypertension of the European Society of Hypertension (ESH) and of the European Society of Cardiology (ESC). Eur Heart J 2013; 34(28): 2159-219.

[5] Vandenbroucke JP, von EE, Altman DG, et al. Strengthening the Reporting of Observational Studies in Epidemiology (STROBE): explanation and elaboration. PLoS Med 2007; 4(10): e297.

[6] Theobald K, Capan M, Herbold M, Schinzel S, Hundt F. Quality assurance in non-interventional studies. Ger Med Sci 2009; 7: Doc29.

[7] De Backer G, Petrella RJ, Goudev AR, Radaideh GA, Rynkiewicz A, Pathak A. Design and methodology of POWER, an open-label observation of the effect of primary care interventions on total cardiovascular risk in patients with hypertension. Fundam Clin Pharmacol 2013; 27(2): 210-5

[8] Conroy RM, Pyorala K, Fitzgerald AP, et al. Estimation of ten-year risk of fatal cardiovascular disease in Europe: the SCORE project. Eur Heart J 2003; 24(11): 987-1003.

[9] Wilson PW, D'Agostino RB, Levy D, Belanger AM, Silbershatz H, Kannel WB. Prediction of coronary heart disease using risk factor categories. Circulation 1998; 97(18): 1837-47.

[10] Goudev A, Berrou JP, Pathak A, on behalf of the POWER Investigators. Effect of eprosartan-based therapy on systolic blood pressure and total cardiovascular risk in a large international population: preliminary report of the observational POWER study. Vasc Health Risk Manag 2012; 8: 563-8.

[11] De Backer G, Petrella RJ, Goudev AR, Radaideh GA, Rynkiewicz A, Pathak A. Effect of antihypertensive therapy on SCOREestimated total cardiovascular risk: results from an open-label, multinational investigation-the POWER survey. Int J Hypertens 2013; 2013: 165789 .

[12] Abraham I, MacDonald K, Hermans C, et al. Real-world effectiveness of valsartan on hypertension and total cardiovascular risk: review and implications of a translational research program. Vasc Health Risk Manag 2011; 7: 209-35.

[13] Lins R, Aerts A, Coen $\mathrm{N}$, et al. Effectiveness of amlodipinevalsartan single-pill combinations: hierarchical modeling of blood pressure and total cardiovascular disease risk outcomes (the EXCELLENT study). Ann Pharmacother 2011; 45(6): 727-39.
[14] Lins R, Coen N, Aerts A, et al. Modelling of blood pressure and total cardiovascular risk outcomes after second-line valsartan therapy: the BSCORE study. Arch Cardiovasc Dis 2011; 104(8-9): 428-34.

[15] Kintscher U, Bramlage P, Paar WD, Thoenes M, Unger T. Irbesar$\tan$ for the treatment of hypertension in patients with the metabolic syndrome: a sub analysis of the Treat to Target post authorization survey. Prospective observational, two armed study in 14,200 patients. Cardiovasc Diabetol 2007; 6: 12.

[16] Parhofer KG, Munzel F, Krekler M. Effect of the angiotensin receptor blocker irbesartan on metabolic parameters in clinical practice: the DO-IT prospective observational study. Cardiovasc Diabetol 2007; 6: 36

[17] Bramlage P, Pittrow D, Kirch W. The effect of irbesartan in reducing cardiovascular risk in hypertensive type 2 diabetic patients: an observational study in 16,600 patients in primary care. Curr Med Res Opin 2004; 20(10): 1625-31.

[18] Bonner G, Landers B, Bramlage P. Candesartan cilexetil/hydrochlorothiazide combination treatment versus highdose candesartan cilexetil monotherapy in patients with mild to moderate cardiovascular risk (CHILI Triple T). Vasc Health Risk Manag 2011; 7: 85-95.

[19] Mancia G, De Backer G, Dominiczak A, et al. 2007 Guidelines for the Management of Arterial Hypertension: The task force for the management of arterial hypertension of the European Society of Hypertension (ESH) and of the European Society of Cardiology (ESC). J Hypertens 2007; 25(6): 1105-87.

[20] Glynn RJ, L'Italien GJ, Sesso HD, Jackson EA, Buring JE. Development of predictive models for long-term cardiovascular risk associated with systolic and diastolic blood pressure. Hypertension 2002; 39(1): 105-10.

[21] Cooney MT, Dudina A, D'Agostino R, Graham IM. Cardiovascular risk-estimation systems in primary prevention: do they differ? Do they make a difference? Can we see the future? Circulation 2010; 122(3): 300-10.

[22] Marques-Vidal P, Rodondi N, Bochud M, et al. Predictive accuracy and usefulness of calibration of the ESC SCORE in Switzerland. Eur J Cardiovasc Prev Rehabil 2008; 15(4): 402-8.

[23] Panagiotakos DB, Fitzgerald AP, Pitsavos C, Pipilis A, Graham I, Stefanadis C. Statistical modelling of 10-year fatal cardiovascular disease risk in Greece: the Hellenic SCORE (a calibration of the ESC SCORE project). Hellenic J Cardiol 2007; 48(2): 55-63.

[24] Liew SM, Doust J, Glasziou P. Cardiovascular risk scores do not account for the effect of treatment: a review. Heart 2011; 97(9): 689-97.

[25] Szyndler A, Kucharska WA, Dubiela D, et al. SCORE model underestimates cardiovascular risk in hypertensive patients: results of the Polish Hypertension Registry. Blood Press 2011; 20(6): 342-7.

[26] Gomez-Marcos MA, Martinez-Salgado C, Martin-Cantera C, et al. Therapeutic implications of selecting the SCORE (European) versus the D'AGOSTINO (American) risk charts for cardiovascular risk assessment in hypertensive patients. BMC Cardiovasc Disord 2009; 9: 17.

[27] Grover SA, Hemmelgarn B, Joseph L, Milot A, Tremblay G. The role of global risk assessment in hypertension therapy. Can J Cardiol 2006; 22(7): 606-13.

[28] Benetos A. Does blood pressure control contribute to a more successful aging? Hypertension 2005; 46(2): 261-2

[29] El-Gharbawy AH, Nadig VS, Kotchen JM, et al. Arterial pressure, left ventricular mass, and aldosterone in essential hypertension. Hypertension 2001; 37(3): 845-50.

[30] He J, Whelton PK, Appel LJ, Charleston J, Klag MJ. Long-term effects of weight loss and dietary sodium reduction on incidence of hypertension. Hypertension 2000; 35(2): 544-9.

[31] Schirmer H, Lunde P, Rasmussen K. Prevalence of left ventricular hypertrophy in a general population; The tromso study. Eur Heart J 1999; 20(6): 429-38.

[32] Staessen JA, Wang JG, Thijs L. Cardiovascular protection and blood pressure reduction: a meta-analysis. Lancet 2001; 358(9290): 1305-15.

Received: January 11, 2014

Revised: February 28, 2014

Accepted: March 02, 2014

(C) Assen Goudev; Licensee Bentham Open.

This is an open access article licensed under the terms of the Creative Commons Attribution Non-Commercial License (http://creativecommons.org/licenses/by-nc/3.0/) which permits unrestricted, non-commercial use, distribution and reproduction in any medium, provided the work is properly cited. 